Short Communication

\title{
CD44 and vimentin, markers involved with epithelial-mesenchymal transition: A proteomic analysis of sequential proteins extraction of triple-negative breast cancer cells after treatment with all-trans retinoic acid
}

\author{
Dana Strouhalova ${ }^{1}$, Dana Macejova ${ }^{2}$, Marketa Lastovickova ${ }^{1}$, Julius Brtko ${ }^{2}$ and Janette Bobalova ${ }^{1}$ \\ ${ }^{1}$ Institute of Analytical Chemistry of the CAS, Brno, Czech Republic \\ ${ }^{2}$ Institute of Experimental Endocrinology, Biomedical Research Center, Slovak Academy of Sciences, Bratislava, Slovakia
}

\begin{abstract}
This work aimed to provide, in one isolation and separation step, an overview of the content of proteins with different solubility after treatment with all-trans retinoic acid, which is considered to be an important therapeutic agent, predominantly in acute promyelocytic leukemia. Breast, ovarian, bladder, and skin cancers have been demonstrated to be suppressed by retinoic acid, as well. The bottom-up proteomic strategies were applied for the analysis of proteins extracted from triple-negative breast cancer MDA-MB-231 cells utilizing a commercially manufactured kit. The gel electrophoresis followed by MALDI-TOF MS analysis was used for protein determination. By employing PDQuest ${ }^{\text {tw }}$ software, we identified several proteins affected by all-trans retinoic acid. Two proteins, vimentin and CD44, which are associated with the epithelial-mesenchymal transition, were selected for a detailed study. We have found that all-trans retinoic acid results in significantly reduced levels of vimentin and CD44 in both the cytoplasmic and membrane fractions. A significant effect was particularly evident in CD44, where protein level in the cytoplasmic fraction was almost completely suppressed.
\end{abstract}

Key words: Breast cancer - All-trans retinoic acid - Proteins - Biomarker - Sequential protein extraction

The knowledge of the structure, function, and amount of specific proteins associated with the epithelial-mesenchymal transition (EMT) process is essential for the development of effective diagnostic approaches to breast cancer with the perspective of diagnosing and treating malignancies (Neagu et al. 2019). EMT is characterized by the downregulation of epithelial markers and the upregulation of the mesenchymal markers. Of the known breast cancer markers, attention has been drawn to vimentin (VIME), which is a marker of the mesenchymal phenotype (Satelli and Li 2011) as well as CD44, which is a transmembrane glycoprotein of which expression is associated with resistance to therapy and poorer prognosis of many cancers (Ahrens et al. 2001; Li et al. 2007). Both proteins are expressed in a large number of

Correspondence to: Janette Bobalova, Institute of Analytical Chemistry of the CAS, Veveři 97, 60200 Brno, Czech Republic E-mail: bobalova@iach.cz variants resulting from their posttranslational modifications (phosphorylation, glycosylation, glycosaminoglycanation). Because alternative splicing and posttranslational modifications generate many different sequences, including, perhaps, tumor-specific sequences, the production of anti-tumorspecific agents may be a realistic therapeutic approach (Eibl et al. 1995).

CD44 overexpression is a characteristic marker for tumorigenic cancer cells (TCC) population of breast cancer (Al-Hajj et al. 2003), colon (Dalerba et al. 2007), pancreas (Li et al. 2007) and prostate (Collins et al. 2005). To date, a number of other TCC markers have been described that are associated with tumorigenicity, strain, apoptosis, and invasiveness. In many cancers, high levels of CD44 expression are not always associated with adverse outcomes (Chen et al. 2018). Current findings have shown that different variants of CD44 are expressed in human tumors and the prognosis can be estimated according to the type of isoform. Various 
research groups analyzing the same neoplastic disease came to conflicting conclusions about the correlation between CD44 expression and disease prognosis, probably due to differences in methodology (Eibl et al. 1995; Naor et al. 2002). These problems need to be solved and further studies are needed to determine the prognostic value of CD44 and its variant isoforms.

MDA-MB-231, a triple-negative breast cancer model, was used in this study to evaluate and compare membrane and cytoplasmic proteins after retinoic acid isomer treatment. Proteins were extracted using a commercially available kit, separated on SDS-PAGE, and characterized by MALDITOF/TOF MS/MS.

The cancer cell culture was purchased from the HPACC (Salisbury, Great Britain). Cells were grown and passaged routinely as monolayer culture. For experiments, the cells were seeded into Petri dishes $(6 \mathrm{~cm}$ diameter, TPP, Switzerland) at $1.2 \times 10^{6}$ cells/dish density in Dulbecco's modified Eagle's medium (DMEM) supplemented with $10 \%$ fetal bovine serum (FBS), antibiotics (penicillin, streptomycin, gentamicin) and treated for $48 \mathrm{~h}$ with $1 \mu \mathrm{mol} / \mathrm{l}$ all-trans retinoic acid (ATRA) in a humidified atmosphere of $5 \%$ $\mathrm{CO}_{2}$ and $95 \%$ air at $37^{\circ} \mathrm{C}$. A stock solution of ATRA was originally dissolved in ethanol, and an equal volume of ethanol (final concentration $<0.02 \%$ ) was added to the control cells. Then cells were washed twice with ice-cooled PBS. The sequential protein extraction was made according to an instruction manual of ReadyPrep ${ }^{\mathrm{m}}$ Protein Extraction Kit Bio Rad.

Proteomic analysis of membrane proteins is challenged by the protein solubility and detergent incompatibility with MS analysis. Here, we used the ReadyPrep protein extraction kit which is a simple, rapid, and reproducible method to prepare protein fractions highly enriched in the membrane and cytoplasmic proteins. This approach makes it possible to reduce the complexity of the sample in order to improve the chances of identifying low-occurring proteins and to simplify proteomic studies. The advantage of this procedure is that the kit does not require the use of ultracentrifugation which is commonly used for these purposes. The fractionation protocol used in this work involved a separation of membrane proteins using Triton X-114 detergent (Bordier 1981; Santoni et al. 2000a, 2000b). The sample was homogenized in the membrane protein extraction buffers and incubated at $37^{\circ} \mathrm{C}$ and centrifuged. The resulting sample was divided into two phases, an upper aqueous phase (cytoplasmic) and a lower detergent-rich phase (membrane). Both protein fractions, hydrophobic and hydrophilic parts, were purified using the ReadyPrep ${ }^{\text {TM }}$ 2-D Cleanup Kit by Bio-Rad for further analyses and gel electrophoresis separation. The purification procedure resulted in quantitative precipitation and protein concentration in the sample while reducing the amount of salts and other substances from the isolation procedure. The final protein pellets after each precipitation step were dissolved in a Laemmli sample buffer and ready for use in gel electrophoresis. After briefly being boiled $\left(10 \mathrm{~min}, 95^{\circ} \mathrm{C}\right)$ in a water bath, samples were applied onto the $12 \%$ SDS gel. Separations were performed at constant voltage $140 \mathrm{~V}$. The visualization was carried out using Coomassie Brilliant Blue G-250 dye. Stained protein bands were excised from the gel and digested (after reduction with $10 \mathrm{mM}$ dithiothreitol and subsequent alkylation with $55 \mathrm{mM}$ iodoacetamide) with trypsin (digestion buffer: $50 \mathrm{mM} \mathrm{NH}_{4} \mathrm{HCO}_{3}, 5 \mathrm{mM} \mathrm{CaCl}_{2}, 12.5 \mathrm{ng} / \mu \mathrm{l}$ of enzyme) overnight at $37^{\circ} \mathrm{C}$. The resulting tryptic peptides were extracted from the gel by $0.1 \%$ trifluoroacetic acid (TFA) and acetonitrile (1:1, v/v). For mass spectrometric analyses, the extracts were purified by ZipTip $\mathrm{C}_{18}$ (Millipore). A solution of a-cyano-4-hydroxycinnamic acid ( $10 \mathrm{mg} / \mathrm{ml}$ in acetonitrile/0.1\% TFA, 1:1, v/v) was used for both MS and MS/MS analysis of peptides. MALDI MS experiments in positive ion reflectron mode were performed on AB SCIEX TOF/TOF ${ }^{\mathrm{mm}}$ 5800 System (AB SCIEX, Framingham, MA, USA) equipped with a $1 \mathrm{kHz} \mathrm{Nd}$ :YAG laser. Acquired mass spectra were processed using 4000 Series Explorer software and the data were submitted to the Mascot database searching. Protein identifications were assigned using the SwissProt database with taxonomy restriction to Homo sapiens. Maximum tolerance for peptide masses, as well as fragment error, was set to 0.6 Da. Additional parameters used: enzyme trypsin; allowed missed cleavages: up to one, fixed modification: carbamidomethyl, no variable modification; peptide charge: +1; monoisotopic masses; instrument MALDI-TOF/TOF.

In this work, we analyzed and compared the protein profiles of the membrane and cytoplasmic fractions of MDAMB-231 cells after treatment with ATRA.

Our previous studies have shown that the natural retinoid ATRA, a cognate ligand of nuclear retinoic acid receptors (RARs), is a promising agent that affects the proteomic profile of cancer cells (Flodrova et al. 2015, 2017). ATRA belongs to a class of retinoids that are known to have a wide range of functions (Alizadeh et al. 2014). Breast, lung, prostate, ovarian, bladder, and skin cancers have been demonstrated to be suppressed by ATRA (Chen et al. 2014). ATRA is known for several decades for its therapeutic effects due to antiproliferative and apoptosis-inducing action, and thus to act in the treatment or prevention of cancer (Carlberg et al. 1993). Furthermore, they inhibit carcinogenesis and suppress tumour growth and invasion in various tissues (Shi et al. 2019), which was the main reason, why ATRA has been used in our studies. The presented study consists of several aims: $i)$ to perform a basic comparison of the membrane and cytoplasmic fractions of MDA-MB-231 cells based on SDS-gels protein profiles; $i$ ) to identify the major proteins related to EMT; iii) to quantify VIME and CD44 after treatment of ATRA. 
First, we compared the membrane and cytoplasmic fractions of both control cells and cells after treatment. Figure 1A shows the protein profiles of the non-treated (control) fractions. Visual inspection of the protein pattern indicated that the membrane and the cytoplasmic fraction share some similarities. On the other hand, significant differences in the electrophoretic profiles of both fractions were observed at molecular weights of approximately $30-50 \mathrm{kDa}$ (Fig. 1A, B). In addition, considerable changes between fractions after treatment in the higher molecular masses $(80-110 \mathrm{kDa})$ were observed (Fig. 1B). The bands showing differences between fractions were cut off and used for further proteomic evaluation including gel tryptic digestion, MALDI-TOF MS. Additional MS/MS analysis of individual peptides and following database searching resulted in the identification of the proteins summarized in Table 1 and Table 2. Selected important proteins are indicated on the SDS gels and are also listed in bold in the tables.

Among proteins with regard to EMT, of importance are predominantly VIME and CD44. As expected, these wellknown human breast cancer markers were identified in mass area about $55 \mathrm{kDa}$ (VIME) and about $85 \mathrm{kDa}$ (CD44) in our experiment. In addition, a high molecular weight form of VIME (VIME HMW) has also been identified, the occur-
A

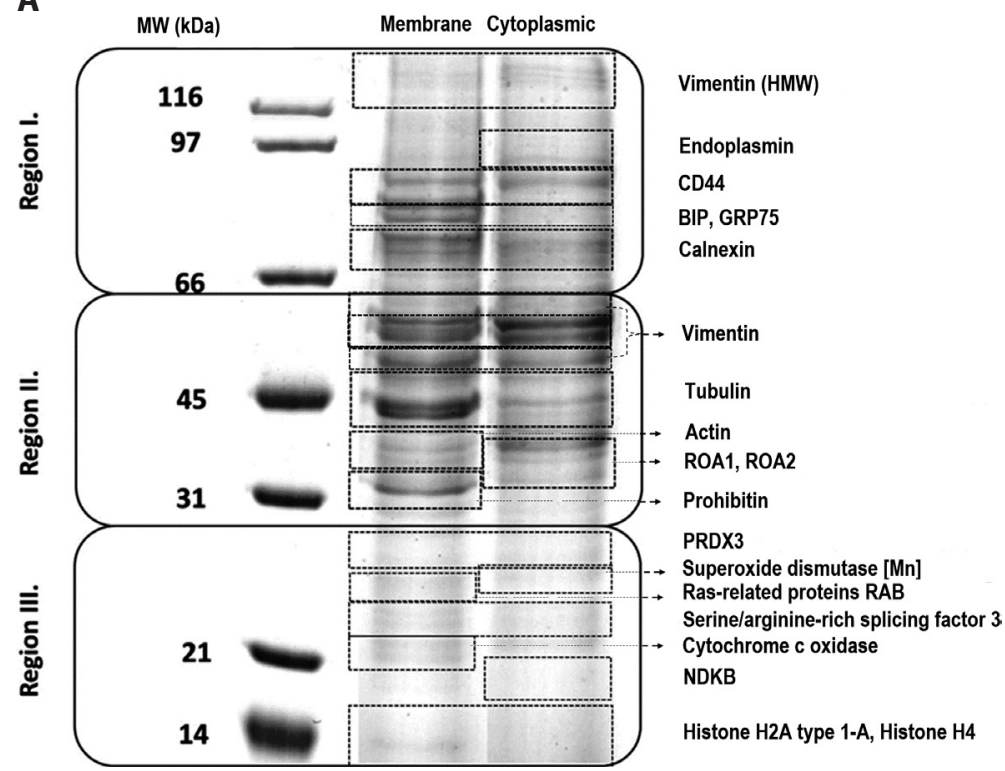

B

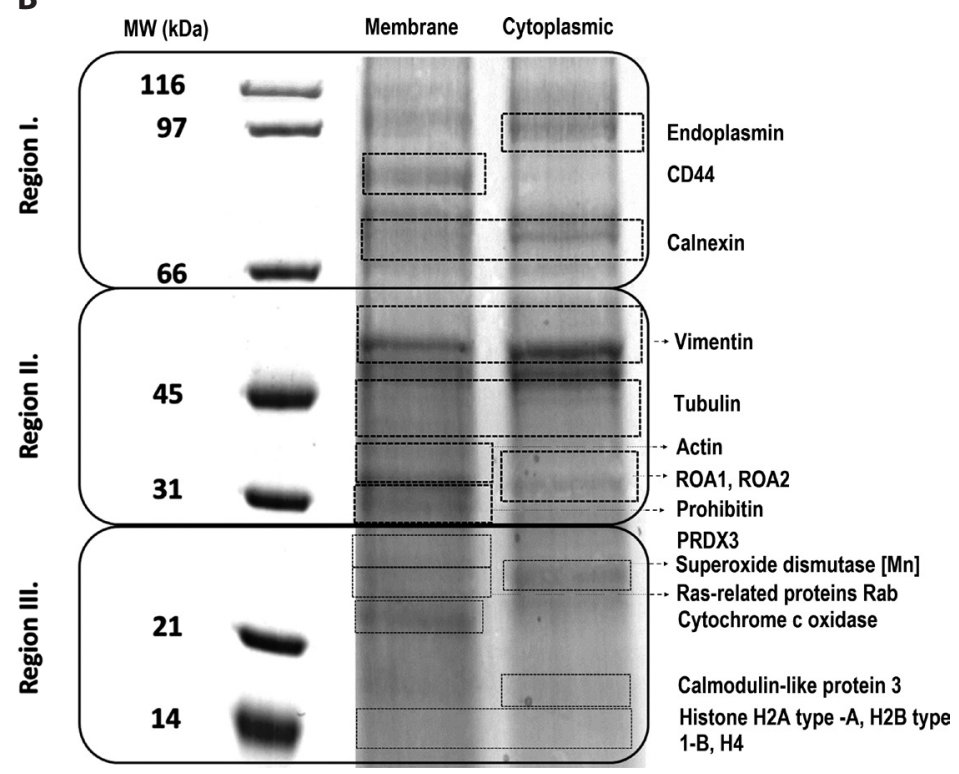

Figure 1. SDS-PAGE separation of the membrane and cytoplasmic proteins of MDA-MB-231 cells. A. Nontreated sample (control sample). B. Sample after 48-h treatment with ATRA. The bands showing differences between fractions were cut off and used for further proteomic evaluation including gel tryptic digestion, MALDI-TOF MS. Selected important proteins are listed on the SDS gel and are shown in bold in the tables. MW, molecular weight. 


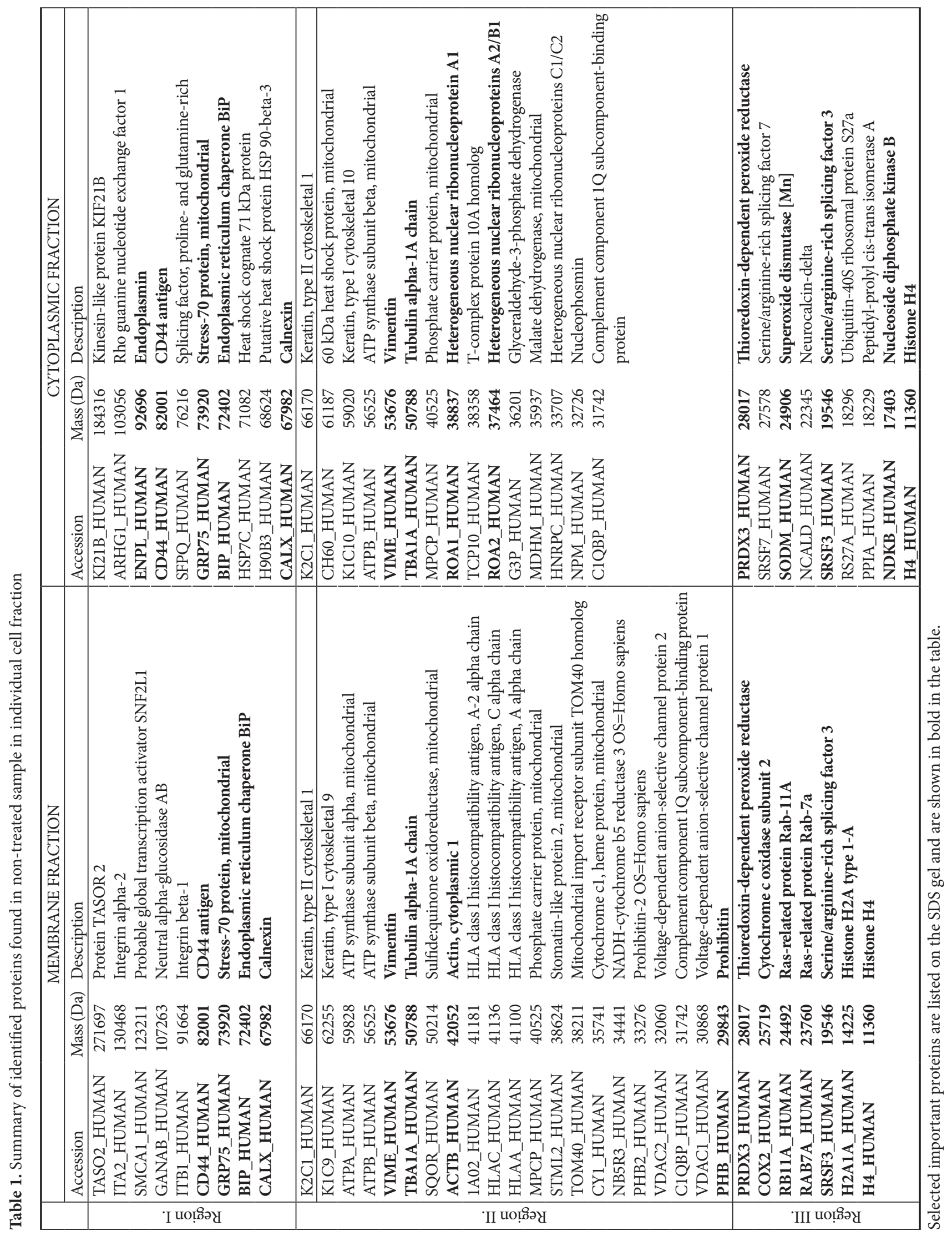




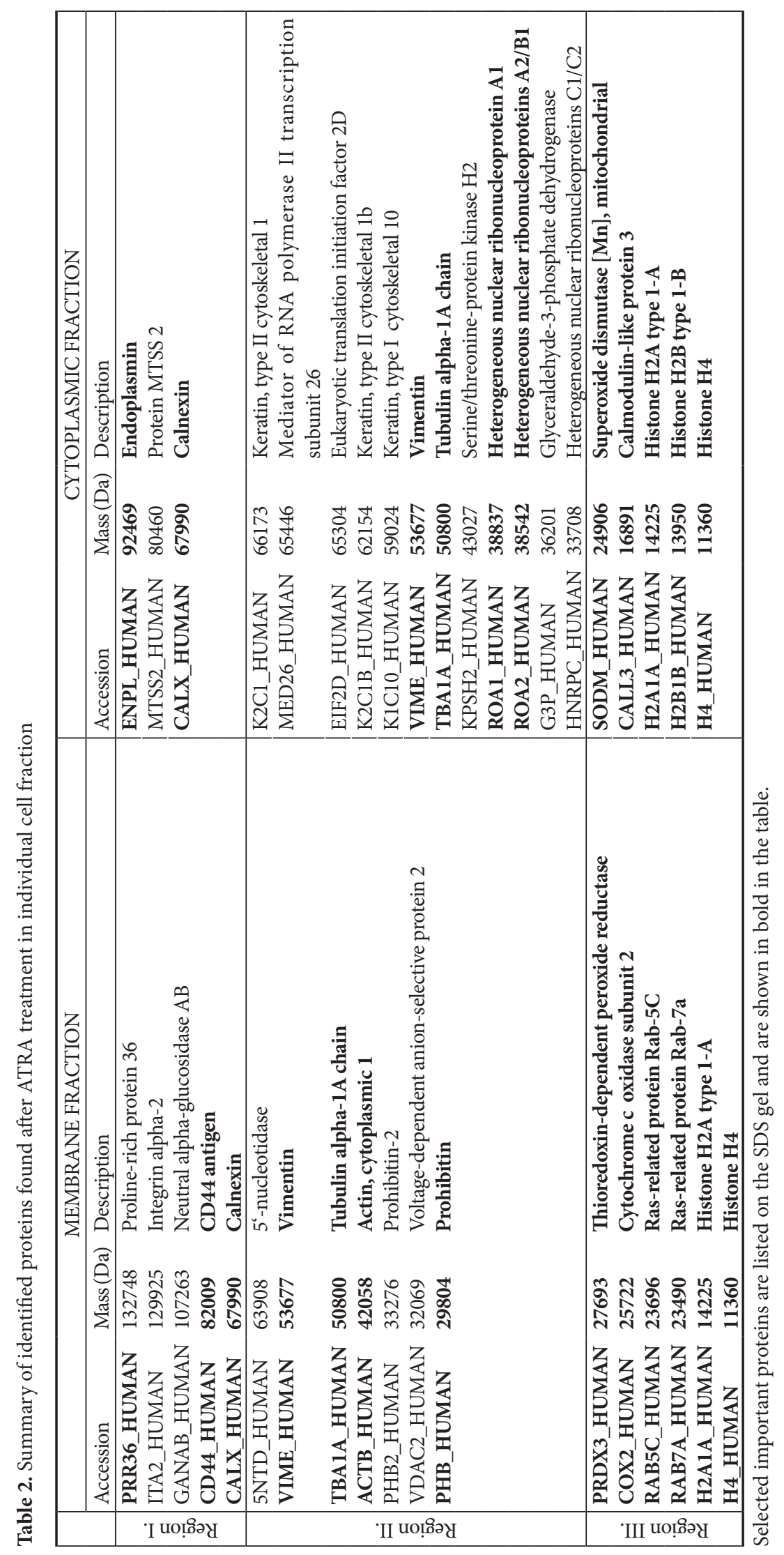


rence of which may explain its ability to form a dimer and possible modifications (Qin and Buehler 2010).

For deeper analysis, the obtained 1D maps were processed by PDQuest software ${ }^{\mathrm{Tm}}$ and compared with a focus on quantitative and qualitative changes. The changes were monitored in the control samples and the samples after treatment. The comparative data were obtained from three independent replicates from each sample (control and ATRA treated) where the chosen spots were used for the pairwise comparisons of relative protein amount. The quantification of chosen proteins in spots was then expressed as the sum of pixel intensities in a given spot. To eliminate some of the image differences caused by the gel staining and de-staining process, the normalization between individual gel images was performed. Obtained data based on PDQuest software analyses were presented as mean \pm SD (standard deviation) from three independent experiments. Statistical analyses were performed with Student's $t$-test. Differences between more than two groups were assessed by one-way analysis of variance (ANOVA) followed by the Student NewmanKeuls method. Differences with $p<0.05$ were considered as statistically significant.

Based on the results obtained, the identified proteins were compared according to their expression influenced by ATRA. Significant effects were seen mainly in VIME as well as in its HMW form, where the protein levels in the membrane and cytoplasmic fraction were almost completely suppressed after treatment with ATRA (see Fig. 2).

The reduction effects of ATRA were also visible in cases of CD44. The obtained PDQuest data report the most significant decrease of cytoplasmic CD44 level for treatment by the

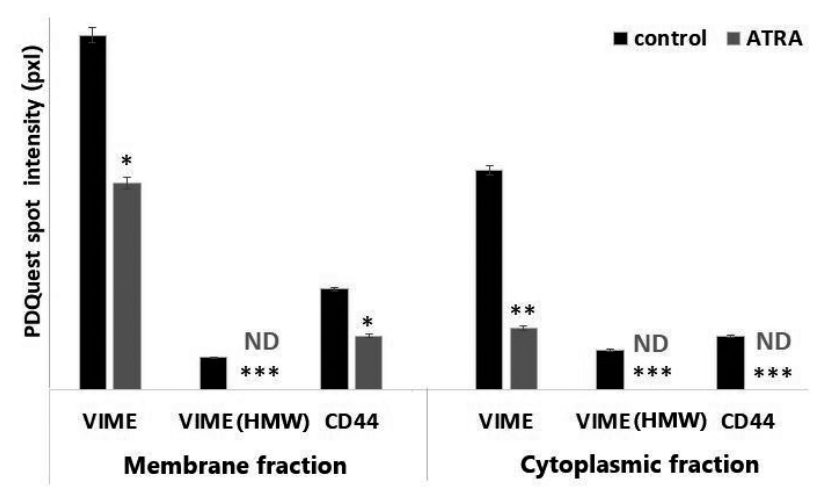

Figure 2. Graph expression of VIME and CD44 representation after treatment with ATRA. The level of proteins found in individual cell fractions was evaluated according to gel electrophoresis separation and subsequent PDQuest software analyses. The quantitative representation of proteins was based on automated spot matching algorithm and normalization between individual pair gels. Each bar represented the means \pm SD of three separate experiments. ${ }^{\star} p<0.05,{ }^{* *} p<0.01$ and ${ }^{* *} p<0.001$ compared to control sample.
ATRA, where the amount of protein was almost impossible to identify. However, this finding does not correspond to the results obtained with membrane CD44 of which concentration was decreased only partially (Fig. 2).

Recently, several types of treatment with ATRA were carried out on the cell lysis of human triple-negative MDAMB-231 cells. ATRA, 9-cis retinoic acid, and a mixture of these two retinoic receptor ligands were tested by Flodrova et al. (2017). The treatment of MDA-MB-231 cells with triorganotin compounds together with ATRA resulted in an additional reduction of annexin 5, nucleoside diphosphate kinase B and VIME (Strouhalova et al. 2019, 2020). In this work, the hypothesis of these studies which stated that ATRA led to a significant reduction in VIME as well as CD44 protein level was confirmed. Moreover, our findings verified that although alternative splicing can produce a large number of different isoforms of CD44, they all retain a common transmembrane and cytoplasmic domain (Thorne et al. 2004) and therefore it is important to study its presence in both the membrane and cytoplasmic fractions obtained by sequential protein extraction.

In conclusion, this work provides first insights into the presentation of VIME and CD44 in the cytoplasmic and membrane protein fraction in the MDA-MB-231 cells after ATRA treatment. Some types of cancer can become more invasive and malignant after undergoing the EMT process. VIME is one of the types of protein markers of EMT that is present in mesenchymal cells and is involved in cancer progression (Kalluri and Weinberg 2009; Zeisberg and Neilson 2009). Also, some findings suggest that CD44 may provide some growth benefits to some neoplastic cells and therefore could be used as a cancer treatment target (Naor et al. 1997). We are convinced that the present data can help reveal additional aspects of the mechanism of action of all-trans retinoic acid in breast cancer, which we consider a highly desirable.

Acknowledgements. The present study was supported by institutional support RVO:68081715 of the Institute of Analytical Chemistry of the CAS, SAV-18-16, APVV-15-0372 and VEGA2/0171/17 grants.

\section{References}

Ahrens T, Sleeman JP, Schempp CM, Howells N, Hofmann M, Ponta H, Herrlich P, Simon JC (2001): Soluble CD44 inhibits melanoma tumor growth by blocking cell surface CD44 binding to hyaluronic acid. Oncogene 20, 3399-3408 https://doi.org/10.1038/sj.onc.1204435

Al-Hajj M, Wicha MS, Benito-Hernandez A, Morrison SJ, Clarke MF (2003): Prospective identification of tumorigenic breast cancer cells. Proc. Natl. Acad. Sci. USA 100, 3983-3988 https://doi.org/10.1073/pnas.0530291100 
Alizadeh F, Bolhassani A, Khavari A, Bathaie SZ, Naji T, Bidgoli SA (2014): Retinoids and their biological effects against cancer. Int. Immunopharmacol. 18, 43-49 https://doi.org/10.1016/j.intimp.2013.10.027

Bordier C (1981): Phase-separation of integral membrane-proteins in triton X-114 solution. J. Biol. Chem. 256, 1604-1607

Carlberg C, Saurat JH, Siegenthaler G (1993): 9-cis-retinoic acid is a natural antagonist for the retinoic acid receptor response pathway. Biochem. J. 295, 343-346 https://doi.org/10.1042/bj2950343

Chen Ch, Zhao S, Karnad A, Freeman JW (2018): The biology and role of CD44 in cancer progression: therapeutic implications. J. Hematol. Oncol. 11, 64 https://doi.org/10.1186/s13045-018-0605-5

Chen MC, Hsu SL, Lin H, Yang TY (2014): Retinoic acid and cancer treatment. Biomedicine (Taipei) 4, 22 https://doi.org/10.7603/s40681-014-0022-1

Collins AT, Berry PA, Hyde C, Stower MJ, Maitland NJ (2005): Prospective identification of tumorigenic prostate cancer stem cells. Cancer Res. 65, 10946-10951 https://doi.org/10.1158/0008-5472.CAN-05-2018

Dalerba P, Dylla SJ, Park I-K, Liu R, Wang X, Cho RW, Hoey T, Gurney A, Huang EH, Simeone DM, et al. (2007): Phenotypic characterization of human colorectal cancer stem cells. Proc. Natl. Acad. Sci. USA 104, 10158-10163 https://doi.org/10.1073/pnas.0703478104

Eibl RH, Pietsch T, Moll J, Skroch-Angel P, Heider K-H, von Ammon K, Wiestler OD, Ponta H, Kleihues P, Herrlich P (1995): Expression of variant CD44 epitopes in human astrocytic brain tumors. J. Neurooncol. 26, 165-170 https://doi.org/10.1007/BF01052619

Flodrova D, Benkovska D, Macejova D, Bialesova L, Hunakova L, Brtko J, Bobalova J (2015): Proteomic analysis of changes in the protein composition of MCF-7 human breast cancer cells induced by all-trans retinoic acid, 9-cis retinoic acid, and their combination. Toxicol. Lett. 232, 226-232 https://doi.org/10.1016/j.toxlet.2014.09.030

Flodrova D, Toporova L, Lastovickova M, Macejova D, Hunakova L, Brtko J, Bobalova J (2017): Consequences of the natural retinoid/retinoid $\mathrm{X}$ receptor ligands action in human breast cancer MDA-MB-231 cell line: focus on functional proteomics. Toxicol. Lett. 281, 26-34 https://doi.org/10.1016/j.toxlet.2017.09.001

Kalluri R, Weinberg RA (2009): The basics of epithelial-mesenchymal transition. J. Clin. Invest. 119, 1420-1428 https://doi.org/10.1172/JCI39104

Li CW, Heidt DG, Dalerba P, Burant CF, Zhang LJ Asday V, Wicha M, Clarke MF, Simeone DM (2007): Identification of pancreatic cancer stem cells. Cancer Res. 67, 1030-1037 https://doi.org/10.1158/0008-5472.CAN-06-2030

Naor D, Sionov RV, IshShalom D (1997): CD44: Structure, function, and association with the malignant process. Adv. Cancer Res. 71, 241-319 https://doi.org/10.1016/S0065-230X(08)60101-3
Naor D, Nedvetzki S, Golan I, Melnik L, Faitelson Y (2002): CD44 in cancer. Crit. Rev. Clin. Lab. Sci. 39, 527-579 https://doi.org/10.1080/10408360290795574

Neagu M, Constantin C, Bostan M, Caruntu C, Ignat SR, Dinescu S, Costache M (2019): Technology „Lens“ for epithelial-mesenchymal transition process identification in oncology. Anal. Cell Pathol. 2019, 3565970 https://doi.org/10.1155/2019/3565970

Qin Z, Buehler MJ (2010): Structure and dynamics of human vimentin intermediate filament dimer and tetramer in explicit and implicit solvent models. J. Mol. Model. 17, 37-48 https://doi.org/10.1007/s00894-010-0696-6

Santoni V, Molloy M, Rabilloud T (2000a): Membrane proteins and proteomics: Un amour impossible? Electrophoresis 21, 1054-1070 https://doi.org/10.1002/(SICI)1522-2683(20000401)21:6<1054::AID-ELPS1054>3.0.CO;2-8

Santoni V, Kieffer S, Desclaux D, Masson F, Rabilloud T (2000b): Membrane proteomics: Use of additive main effects with multiplicative interaction model to classify plasma membrane proteins according to their solubility and electrophoretic properties. Electrophoresis 21, 3329-3344

https://doi.org/10.1002/1522-2683(20001001)21:16<3329::AID-ELPS3329>3.0.CO;2-F

Satelli A, Li S (2011): Vimentin in cancer and its potential as a molecular target for cancer therapy. Cell. Mol. Life Sci. 68, 3033-3046 https://doi.org/10.1007/s00018-011-0735-1

Shi G, Zheng X, Wu X, Wang S, Wang Y, Xing F (2019): All-trans retinoic acid reverses epithelial-mesenchymal transition in paclitaxel-resistant cells by inhibiting nuclear factor kappa $\mathrm{B}$ and upregulating gap junctions. Cancer Sci. 110, 379-388 https://doi.org/10.1111/cas.13855

Strouhalova D, Toporova L, Lastovickova M, Macejova D, Bobalova J, Brtko J (2019): Novel insights into the combined effect of triorganotin compounds and all-trans retinoic acid on expression of selected proteins associated with tumor progression in breast cancer cell line MDA-MB-231: proteomic approach. Gen. Physiol. Biophys. 38, 135-144 https://doi.org/10.4149/gpb_2018042

Strouhalova D, Macejova D, Mosna B, Bobal P, Otevrel J, Lastovickova M, Brtko J, Bobalova J (2020): Down-regulation of vimentin by triorganotin isothiocyanates-nuclear retinoid $\mathrm{X}$ receptor agonists: A proteomic approach. Toxicol. Lett. 318, 22-29 https://doi.org/10.1016/j.toxlet.2019.10.004

Thorne RF, Legg JW, Isacke CM (2004): The role of the CD44 transmembrane and cytoplasmic domains in co-ordinating adhesive and signalling events. J. Cell Sci. 117, 373-380 https://doi.org/10.1242/jcs.00954

Zeisberg M, Neilson EG (2009): Biomarkers for epithelial-mesenchymal transitions. J. Clin. Invest. 119, 1429-1437 https://doi.org/10.1172/JCI36183

Received: May 18, 2020

Final version accepted: July 7, 2020 